\title{
Avaliação \& Perspectivas da Ciência da Informação e da Arquivologia no Brasil: reflexões em movimento ${ }^{1}$
}

\author{
Angelica Alves da Cunha Marques \\ Doutora; Universidade de Brasília, Brasília, DF, Brasil \\ angelicacunha@unb.br
}

\begin{abstract}
Resumo: Este artigo objetiva compreender os diagnósticos e prognósticos da Ciência da Informação e da Arquivologia apresentados em Avaliação \& Perspectivas. Mediante pesquisa bibliográfica e documental no fundo Conselho Nacional de Desenvolvimento Científico e Tecnológico, considera a relevância da publicação como instrumento estratégico para o desenvolvimento científico e tecnológico. Analisa denominações, definições, relações e recomendações dadas para as duas disciplinas no Brasil. Mais especificamente, retoma os principais avanços e desafios da Arquivologia como disciplina no Brasil. Os resultados indicam denominações, por vezes, incoerentes com as definições apresentadas. A publicação aponta dificuldades de reconhecimento da Ciência da Informação e da Arquivologia no cenário brasileiro, embora elas não comprometam as possibilidades de interlocução entre elas.
\end{abstract}

Palavras-chave: Ciência da Informação. Arquivologia. Avaliação \& Perspectivas. Conselho Nacional de Desenvolvimento e Pesquisa. Desenvolvimento científico.

\section{Introdução}

As primeiras fundações particulares para incentivar a Ciência \& Tecnologia (C\&T), assim como as ideias de criação de muitos conselhos de pesquisa, surgem no âmbito de políticas nacionais, no contexto da primeira grande guerra mundial, quando há o reconhecimento da eficácia da C\&T para a definição das batalhas (MOTOYAMA; NAGAMINI, 1996).

No Brasil, o Conselho Nacional de Desenvolvimento Científico e Tecnológico $(\mathrm{CNPq})$ tem suas origens na década de 1920, com o surgimento da Academia Brasileira de Ciências (ABC) e com as primeiras ideias acerca da necessidade de criação de um conselho de pesquisas (CONSELHO NACIONAL 
DE PESQUISA E DESENVOLVIMENTO CIENTÍFICO E TECNOLÓGICO, 1984; MOTOYAMA, 1985; MOTOYAMA; NAGAMINI, 1996). A ABC recebe o apoio de pesquisadores, cientistas e políticos que acalentam essas ideias, embora falte apoio político do próprio Estado. Fica, então, evidente a necessidade de articulação entre políticos e pesquisadores, que enfrentam muitos desafios em torno dos seus objetivos, até a criação do Conselho Nacional de Pesquisas pela Lei 1.310 , em 15 de janeiro de $1951^{2}$. Nesse contexto, são estruturadas as bases da Tabela de Áreas do Conhecimento (TAC) do CNPq, a qual passa por algumas atualizações (SOUZA, 2004, 2006, 2008) ao longo do tempo, como veremos adiante.

A partir de 1974, o CNPq passa a coordenar o Sistema Nacional de Desenvolvimento Científico e Tecnológico (SNDCT), coordenando a elaboração do Plano Básico de Desenvolvimento Científico e Tecnológico (PBDCT), “[...] braço científico e tecnológico dos Planos Nacionais de Desenvolvimento (PNDs) [...]" (CONSELHO NACIONAL DE DESENVOLVIMENTO CIENTÍFICO E TECNOLÓGICO, 2002, p. 7).

Com a experiência de coordenação da elaboração do II e do III PBDCTs, de 1975 a 1978 e de 1980 a 1985, respectivamente, o CNPq diagnostica, panoramicamente, o sistema de C\&T, no Brasil, mediante quatro rodadas bienais de Avaliação \& Perspectivas (A\&P) (CONSELHO NACIONAL DE DESENVOLVIMENTO CIENTÍFICO E TECNOLÓGICO, 2002). A relevância dessa publicação como termômetro científico pode ser apreendida na explanação do seu objetivo:

[...] o objetivo principal da A\&P, que foi o de auscultar a comunidade quanto aos seus pontos de vista, analisando de forma crítica seu respectivo campo de atividade e promovendo uma reflexão tão profunda quanto possível sobre os "porquês" da situação e sobre os caminhos a seguir. (CONSELHO NACIONAL DE DESENVOLVIMENTO CIENTÍFICO E TECNOLÓGICO, 1982a, p. 10).

Este artigo insere-se em um amplo projeto de pesquisa desenvolvido no âmbito de um estágio pós-doutoral junto ao Programa de Pós-graduação em Ciência da Informação da Universidade de Brasília (UnB) e à École des Chartes 
(Paris, França). Este estudo objetiva compreender a situação da Ciência da Informação e, mais especificamente, da Arquivologia descritas nesse documento, especialmente nas suas versões de 1978 e 1982, mediante uma pesquisa bibliográfica e documental no fundo CNPq. Pensamos que este empreito justifica-se pela relevância da publicação Avaliação \& Perspectivas, complementarmente às TACs, como termômetro histórico da situação dessas disciplinas no Brasil, contraditoriamente de difícil acesso intelectual e físico.

\section{As tabelas de áreas do conhecimento}

Entre os anos de 1951 e 1966, o CNPq reconhece sete setores como áreas do conhecimento: Biologia e Ciências Médicas; Agronomia; Química; Física e Astronomia; Matemática; Geologia ou Ciências da Terra; e Tecnologia. Em 1966, são concebidos mais dois setores (Veterinária e Ciências Sociais) e o setor técnico desaparece dessa classificação (ROMANI, 1982).

Uma década depois, o critério para a classificação das áreas do conhecimento passa a corresponder aos 15 comitês assessores da instituição. E é em 1976 que o CNPq publica a sua primeira TAC, reconhecendo que "A classificação das Áreas do Conhecimento tem por finalidade permitir ao $\mathrm{CNPq}$ e, eventualmente, a outros órgãos e instituições, sistematizar informações sobre o desenvolvimento científico e a formação de recursos humanos para a pesquisa." (CONSELHO NACIONAL DE DESENVOLVIMENTO CIENTÍFICO E TECNOLÓGICO, 1978a, p. 3). Nesse documento, a área de Comunicação abrange as Ciências da Informação como subárea, cujas especialidades são: Sistemas da Informação, Biblioteconomia e Documentação. Já a Arquivologia não aparece nessa classificação.

Em 1978, essa tabela é atualizada e, em 1982, a segunda TAC do CNPq é publicada, hierarquizando áreas, subáreas e especialidades dentro de cinco grandes áreas (SOUZA, 2005). Na grande área "Ciências Humanas, Sociais e Artes", a área denominada como "Ciência da Informação, Biblioteconomia e Arquivologia" é contemplada com duas subáreas e suas respectivas especialidades: (1) Teoria da Informação (Teoria Geral da Informação; 
Processos da Comunicação; Teoria da Classificação; Representação da Informação; e Métodos Quantitativos, Bibliometria e Tratamento da Informação); e (2) Tratamento da Informação (Técnicas de Recuperação da Informação; Processos de Disseminação da Informação; e Organização de Arquivos).

Em 1984, é publicada a terceira TAC, na qual a grande área "Ciências Sociais Aplicadas" abarca a Ciência da Informação (agora no singular) como área, subdividida nas seguintes subáreas: Teoria da Informação (com as especialidades Teoria Geral da Informação; Processos da Comunicação; e Representação da Informação), Biblioteconomia (com as especialidades Teoria da Classificação; Métodos Quantitativos, Bibliometria; Técnicas de Recuperação da Informação; e Processos de Disseminação da Informação) e Arquivologia (com a especialidade Organização de Arquivos). A Arquivologia é, então, contemplada como subárea da área Ciência da Informação (CONSELHO NACIONAL DE DESENVOLVIMENTO CIENTÍFICO E TECNOLÓGICO, 1984; SOUZA, 2004, 2008; SOUZA; STUMPF, 2009).

Essa versão da TAC passa por duas tentativas de revisão, na década de 1990 e no ano de 2005, quando o CNPq, a Coordenação de Aperfeiçoamento de Pessoal de Nível Superior (CAPES) e a Financiadora de Estudos e Projetos (FINEP) compõem uma comissão especial de estudos para propor uma nova tabela, conforme Portaria conjunta do CNPq, CAPES e FINEP, de 2 de março de 2005. Essa TAC teria oito grandes áreas, dentre as quais, as Ciências Socialmente Aplicáveis que, por sua vez, contemplariam a Ciência da Informação, a Biblioteconomia e a Arquivologia como áreas distintas. Entretanto, por diversas razões, essa proposta não se consolida e a tabela em vigor ainda é a de 1984, que possui nove grandes áreas, 76 áreas, 340 subáreas e 867 especialidades. $^{3}$

\section{Avaliação \& Perspectivas como termômetros científicos}

A partir de 1974, a publicação Avaliação \& Perspectivas sintoniza-se a uma das competências dos comitês assessores do CNPq, instituídos pela Resolução 
Normativa RN01/76, como fruto do trabalho de vários pesquisadores representantes das diversas áreas do conhecimento. Essa iniciativa do $\mathrm{CNPq}$ insere-se no âmbito da sua competência de não somente coordenar a elaboração do PBDCT, bem como acompanhar a sua execução, mais especificamente, quanto ao "Desenvolvimento Científico e Formação de Recursos Humanos para a Pesquisa", referidos nesse Plano. Dessa maneira, o documento tem por finalidade, mediante análise qualitativa, “[...] fornecer elementos para que o CNPq se incumba das suas atribuições estatutárias de acompanhar o PBDCT, no que concerne ao desenvolvimento científico e à formação de pesquisadores." (CONSELHO NACIONAL DE DESENVOLVIMENTO CIENTÍFICO E TECNOLÓGICO, 1978b). Nesse sentido, o documento deveria:

[...] fornecer, a órgãos governamentais com responsabilidade no desenvolvimento científico e tecnológico, à empresa brasileira e ao próprio pesquisador, uma visão abrangente das áreas de seu interesse, visando a facilitar, pelo conhecimento, as decisões que a cada um cabe, na importante tarefa de autêntico crescimento a que o País se propõe. (CONSELHO NACIONAL DE DESENVOLVIMENTO CIENTÍFICO E TECNOLÓGICO, 1978b, p. 1).

Os resultados dos trabalhos de 1978 e de 1982 são amplamente divulgados, mediante a publicação dos relatórios de cada área de conhecimento e de um volume de sinopses (CONSELHO NACIONAL DE DESENVOLVIMENTO CIENTÍFICO E TECNOLÓGICO, 1978b, 1978c, 1982a, 1982b, 2002).

\subsection{A Ciência da Informação e a Arquivologia em Avaliação \& Perspectivas: 1978}

A Ciência da Informação, a Biblioteconomia e a Arquivologia são contempladas, nesse documento, somente a partir da sua versão de 1978, quando são estudadas 44 áreas do conhecimento. Contudo, as informações a respeito dessa última disciplina são menos detalhadas do que aquelas das duas primeiras, em razão da ausência de um especialista da área na primeira reunião do grupo 
responsável pela sua redação (CONSELHO NACIONAL DE DESENVOLVIMENTO CIENTÍFICO E TECNOLÓGICO, 1978b).

O primeiro grande desafio desse grupo é a definição da área, reconhecida, provisoriamente, pelo CNPq, como "Documentação e Informação". A sua decisão a respeito pauta-se nos usos internacionais e nacionais, conforme a coordenação das três disciplinas em uma única área, a partir da então denominada "Ciência da Informação, Biblioteconomia e Arquivologia", mesmo ciente da falta de unanimidade dessa opção. Ao comparar as três disciplinas historicamente, o grupo reconhece que:

O fato de a Biblioteconomia e a Arquivologia estarem voltadas para a aplicação de técnicas não quer dizer que no seu âmbito não se realizem pesquisas ou se produzam novos conhecimentos, da mesma forma que a Ciência da Informação não é exclusivamente teórica e desvinculada de aplicações práticas.

Na realidade o conceito de Ciência da Informação - que alguns consideram que seria a categoria mais genérica da qual Biblioteconomia e Arquivologia seriam específicos - é de origem relativamente recente, de contornos ainda em desenvolvimento, enquanto que as duas últimas disciplinas são bastante antigas e com um corpo definido de conhecimentos e técnicas. (CONSELHO NACIONAL DE DESENVOLVIMENTO CIENTÍFICO E TECNOLÓGICO, 1978b, p. 52-53, grifo nosso).

O grupo especifica, assim, os seus objetos de estudo, acabando por reduzir as disciplinas a eles e, no caso da Arquivologia, afirma que "[...] os arquivos lidam com aqueles documentos que foram produzidos como resultado das atividades desenvolvidas por uma pessoa física ou jurídica e que, portanto, documentam essas atividades e têm valor para consulta e pesquisa." (CONSELHO NACIONAL DE DESENVOLVIMENTO CIENTÍFICO E TECNOLÓGICO, 1978b, p. 52).

Ao justificar a inclusão da Arquivologia na referida análise, o mesmo grupo lembra:

[...] o lugar que os arquivos ocupam no sistema de informações de qualquer país. Os materiais de arquivos, principalmente os originários das repartições públicas, são indispensáveis à preservação e reconstrução da memória nacional e constituem, tanto ou mais que os documentos impressos encontrados em bibliotecas, a matéria-prima para o trabalho de pesquisa de historiadores e outros cientistas sociais, sem falar da sua importância como fonte de 
informações técnicas e científicas de valor não exclusivamente histórico. (CONSELHO NACIONAL DE DESENVOLVIMENTO CIENTÍFICO E TECNOLÓGICO, 1978b, p. 53).

Contudo, a Ciência da Informação é apresentada como o campo mais amplo, no qual a Biblioteconomia e a Arquivologia apareceriam como disciplinas aplicadas:

\begin{abstract}
No contexto do presente documento, Ciência da Informação designa o campo mais amplo, de propósitos investigativos e analíticos, interdisciplinar por natureza, que tem por objeto o estudo dos fenômenos ligados à produção, organização, difusão, e utilização de informações em todos os campos do saber.

A Biblioteconomia e a Arquivologia são disciplinas aplicadas, que tratam da coleta, organização e difusão de informações preservadas em diferentes tipos de suportes materiais. (CONSELHO NACIONAL DE DESENVOLVIMENTO CIENTÍFICO E TECNOLÓGICO, 1978b, p. 52).
\end{abstract}

Esse posicionamento é superficialmente justificado no documento, que retoma recomendações da Organização das Nações Unidas para a Educação, a Ciência e a Cultura (UNESCO) em relação à integração dos serviços de bibliotecas, informação e arquivos, especialmente aquelas da Conferência Intergovernamental sobre Planejamento de Infraestruturas Nacionais de Documentação, Bibliotecas e Arquivos (Paris, 1974). Segundo o documento, "As recomendações dessa conferência foram endossadas por todos os congressos brasileiros de especialistas nesta área, após 1975." (CONSELHO NACIONAL DE DESENVOLVIMENTO CIENTÍFICO E TECNOLÓGICO, 1978b, p. 54).

Assim, no contexto internacional, a Ciência da Informação teria alcançado reconhecimento com

[...] uma posição comparável à de outras áreas do conhecimento, tradicionalmente reputadas como de maior prestígio, tanto no que se refere à formação de recursos humanos e às atividades de pesquisa $\mathrm{e}$ desenvolvimento como no que diz respeito à sua estrutura profissional e organizacional, avaliada em termos de produção de trabalhos e de sua influência no setor social. (CONSELHO NACIONAL DE DESENVOLVIMENTO CIENTÍFICO E TECNOLÓGICO, 1978b, p. 54). 
O documento apresenta a trajetória do Arquivo Nacional e da Biblioteca Nacional, destacando as suas iniciativas pioneiras, no Brasil, quanto à formação de pessoal na Arquivologia e Biblioteconomia. Reconhece a identidade dessas disciplinas, embora, contraditoriamente, não respeite essa identidade na sua proposta de denominação de área. No âmbito da pós-graduação, retoma, inclusive, iniciativas de mestrados em Biblioteconomia que, futuramente, expandir-se-iam para a Ciência da Informação.

Tendo em vista o escopo da nossa pesquisa e destacando a parte que mais nos interessa (e que não é realçada no documento em análise), a situação da Arquivologia é, brevemente, descrita em dois parágrafos:

O desenvolvimento desta área tem sido muito lento. Faz apenas poucos anos o Conselho Federal de Educação estabeleceu o currículo mínimo dos cursos de graduação. Atualmente, além do já mencionado curso da FEFIERJ, está em funcionamento um curso de Arquivologia da Universidade Federal de Santa Maria. Prevê-se para 1979 o início de cursos de graduação na Universidade Federal Fluminense, na Universidade Federal do Paraná, e na Universidade Federal [sic] de Brasília. Acha-se em tramitação, na Universidade Federal Fluminense, um projeto de curso de aperfeiçoamento para professores do ensino superior de Arquivologia.

Desconhece-se planos de criação de programa de pós-graduação. (CONSELHO NACIONAL DE DESENVOLVIMENTO CIENTÍFICO E TECNOLÓGICO, 1978b, p. 60).

Em síntese, as dificuldades pelas quais as três áreas analisadas passavam são assim apresentadas:

Ainda que certas instituições representativas tenham uma longa história - a Biblioteca Nacional e o Arquivo Nacional surgiram na primeira metade do século passado e o IBICT tem mais de vinte anos de existência - a evolução desta área, em termos de geração de conhecimentos e adaptação às mudanças sociais, tem sido lenta, aleatória e não raro sujeita a longos períodos de estagnação. Vista à luz dos progressos alcançados em outros países, a impressão que se tem é de que faz muito pouco tempo que, no Brasil, as três disciplinas aqui analisadas começaram a se elevar ao nível das outras áreas do conhecimento que já encontram seu lugar no sistema social e acadêmico. De certa maneira, a visão que se tem do setor é a de um campo ainda por explorar e em que as realizações alcançadas estão muito aquém do que deve ser feito.

[...] No caso da Arquivologia, o quadro é muito mais grave, pois somente agora se inicia o processo de implantação dos cursos de graduação em instituições universitárias. (CONSELHO 
Ainda em relação às dificuldades enfrentadas pela Arquivologia no cenário nacional, é lembrado o descaso quanto aos arquivos, que tem gerado perdas irrecuperáveis de documentos valiosos.

Outro aspecto, que parece bastante relevante, diz respeito ao apontamento do grupo em relação à importação acrítica de técnicas e de padrões estrangeiros, pelos pesquisadores brasileiros, gerando "[...] uma grave dependência que tende a inibir o processo criativo e a estimular a arbitrária transferência de tecnologias." (CONSELHO NACIONAL DE DESENVOLVIMENTO CIENTÍFICO E TECNOLÓGICO, 1978b, p. 64).

Ao cumprir a segunda parte da sua designação, o documento Avaliação \& Perspectivas apresenta perspectivas para a área que ainda parecem bastante atuais, particularmente para a Arquivologia:

\footnotetext{
Mas a produção científica ainda é limitada e pouco animadora, parecendo que as informações e conhecimentos produzidos não foram suficientes para influir no processo de aperfeiçoamento e/ou mudança da realidade. Aliás, só há poucos anos é que esta realidade passou a merecer um maior número de estudos objetivos, os quais, antes, estavam mais voltados para temas e ideias distantes do contexto local.

Não seria arriscado afirmar que todos os setores de pesquisa neste campo precisam expandir-se. (CONSELHO NACIONAL DE DESENVOLVIMENTO CIENTÍFICO E TECNOLÓGICO, 1978b, p. 61-62).
}

Diante desse quadro, o grupo tece diversas recomendações, dentre as quais destacamos o desenvolvimento de um projeto específico para a formação de mestres e doutores em Arquivologia.

\subsection{A Ciência da Informação e a Arquivologia em Avaliação \& Perspectivas:} 1982

Cinco anos depois, novamente no âmbito do Plano Nacional de Desenvolvimento, o CNPq publica outro documento Avaliação \& Perspectivas, no qual reúne e registra a colaboração de vários pesquisadores e instituições, 
como “[...] um subsídio importante para a formulação e execução da política científica e tecnológica do país [...]", ou seja, "[...] um mecanismo através do qual os pesquisadores na área científica podem e devem participar na definição das diretrizes e prioridades da política científica e tecnológica." (CONSELHO NACIONAL DE DESENVOLVIMENTO CIENTÍFICO E TECNOLÓGICO, 1982a, p. 5-7).

Essa versão do documento retoma o histórico das publicações anteriores, ao reiterar o seu objetivo:

Os documentos da A\&P 82 têm por objetivo fazer uma análise crítica do estado em que se encontra a ciência brasileira. A partir desta análise devem apresentar as perspectivas para o desenvolvimento da ciência nos próximos anos, indicando caminhos, ações e possibilidades para uma evolução constante e segura, condizente com o desenvolvimento e com a posição que o país pretende ocupar na comunidade das nações. (CONSELHO NACIONAL DE DESENVOLVIMENTO CIENTÍFICO E TECNOLÓGICO, 1982a, p. 8).

Em Avaliação \& Perspectivas de 1982, sete áreas do conhecimento abarcam 66 subáreas. A área Ciências Sociais Aplicadas, por sua vez, contempla dez subáreas, dentre as quais a Biblioteconomia; ainda que o documento a apresente, novamente, como "Ciência da Informação, Biblioteconomia e Arquivologia" (CONSELHO NACIONAL DE DESENVOLVIMENTO CIENTÍFICO E TECNOLÓGICO, 1982a, p. 9) e como "Biblioteconomia e Arquivologia" (CONSELHO NACIONAL DE DESENVOLVIMENTO CIENTÍFICO E TECNOLÓGICO, 1982b). Assim como sua versão anterior, esse documento ratifica a falta de consenso em relação às áreas às quais se refere. Dessa forma, define a Ciência da Informação:

A Ciência da Informação, um campo de saber ainda emergente se comparado com as outras ciências, é geralmente descrita como interdisciplinar por natureza, abrangendo um amplo leque de interesses ligados à geração, organização, recuperação, transmissão e uso da informação, que incluiria entre outras disciplinas, a Biblioteconomia. (CONSELHO NACIONAL DE DESENVOLVIMENTO CIENTÍFICO E TECNOLÓGICO, 1982a, p. 74). 
Mesmo tendo a sua antiguidade e definição reconhecidas, essa última disciplina é sobreposta à Ciência da Informação.

A Arquivologia, por sua vez, é apresentada separadamente, por outra redatora ${ }^{4}$ que registra o panorama dos principais problemas da área no Brasil, sinalizando a necessidade de: definição do campo teórico-epistemológico da disciplina; implantação do Sistema Nacional de Arquivos; regulação da Lei de Arquivo (à época em tramitação); implantação de sistemas estaduais de arquivo; tratamento adequado dos arquivos privados; criação de órgãos de fiscalização do exercício da profissão de arquivista, já reconhecida por lei; ampliação dos cursos de formação específica em Arquivologia e/ou integrada à Biblioteconomia e à Ciência da Informação, no âmbito da graduação; criação de cursos de pós-graduação voltados para a Arquivologia; maior controle e divulgação de acervos arquivísticos; definição de métodos e técnicas arquivísticas; desenvolvimento de estudos quanto à administração e, mais especificamente, à avaliação de documentos; promoção do acesso à informação e aos documentos públicos; identificação, preservação e divulgação dos arquivos impressos decorrentes das atividades da área-fim das instituições públicas; planejamento da política voltada para a microfilmagem de documentos; estudos relacionados à restauração e conservação de documentos; automação de arquivos, tendo em vista a sua divulgação e o seu acesso; e desenvolvimento de programas de história oral. Nesse quadro, é apresentado, ainda, o relevante papel da Associação dos Arquivistas Brasileiros (AAB), com destaque para os seus eventos (Congresso Brasileiro de Arquivologia - CBA) e para o seu periódico (Arquivo \& Administração), e para o International Council on Archives (ICA), em suas parcerias com outras instituições internacionais.

Diante da sua breve avaliação, a redatora tece algumas recomendações, diante das perspectivas da área, das quais destacamos duas: a necessidade de se mudar a mentalidade dos administradores, no âmbito das instituições de ensino e das instituições públicas, para a implementação de serviços de arquivos e para a valorização desses, “[...] como instrumento de administração, estudo e planejamento." (CONSELHO NACIONAL DE DESENVOLVIMENTO CIENTÍFICO E TECNOLÓGICO, 1982a, p. 115); e a análise do mundo do 
trabalho, diante das demandas de formação de nível superior e técnico, inclusive para a formação de professores para a docência arquivística.

\section{A Arquivologia: avaliação em retrospectiva}

Considerando os principais problemas dos arquivos e da Arquivologia apontados por Nilza Teixeira, na versão de Avaliação \& Perspectivas de 1982, é possível retomar os desafios e os avanços da área na sua busca por autonomia no campo científico, mais particularmente, no campo da informação (MARQUES, 2013).

Em 1991, após anos de tentativas, o Sistema Nacional de Arquivos (SINAR) e o Conselho Nacional de Arquivos (CONARQ) são criados, com a Lei 8.159, de 21 de janeiro, na perspectiva de uma política nacional de arquivos. Essa lei é o mais importante marco legal no cenário arquivístico brasileiro, ao reconhecer não somente a responsabilidade do Estado na gestão e na preservação de documentos de arquivo, mas também o direito do cidadão de acesso à informação; ao apresentar importantes conceitos arquivísticos, a organização de instituições arquivísticas públicas e a classificação dos documentos quanto ao acesso e ao sigilo (BRASIL, 1991). ${ }^{5}$ A partir dessa lei, sistemas estaduais de arquivo vêm sendo paulatinamente implantados, ainda que a realidade esteja muito aquém das necessidades de gestão e de preservação dos documentos públicos (SANTOS, 2005).

Os arquivos privados, por sua vez, ainda que reconhecidos na Lei de Arquivos e que sejam temáticas de eventos científicos, ainda não recebem o tratamento necessário e adequado, diante das suas especificidades.

Como ainda não há um conselho de Arquivologia no Brasil, as atividades desempenhadas pelos arquivistas brasileiros não são fiscalizadas. Profissionalmente, os arquivistas são representados por 12 associações, ${ }^{6}$ embora nem todos os estados que abriguem cursos de Arquivologia tenham associações profissionais de arquivistas (SOUZA, 2011).

Especialmente após os anos 2000, os cursos de graduação em Arquivologia são expandidos no âmbito do Programa do Governo Federal de 
Apoio a Planos de Reestruturação e Expansão das Universidades Federais Brasileiras (REUNI). A maioria dos 17 cursos em funcionamento está vinculada academicamente à Ciência da Informação, ${ }^{7}$ o que tem propiciado diálogos acadêmicos e interlocuções teóricas e epistemológicas entre as duas disciplinas (MARQUES, 2013).

Ao longo do tempo, vários cursos de pós-graduação lato sensu são criados, dos quais podemos destacar o Curso de Organização de Arquivos do Instituto de Estudos Brasileiros (IEB) da Universidade de São Paulo (USP), que congregava profissionais com diversas formações em torno da especialização em Arquivologia, entre os anos de 1986 e 2008 (OLIVEIRA, 2014). Mais recentemente, é criado o Mestrado Profissional em Gestão de Documentos e Arquivos na Universidade Federal do Estado do Rio de Janeiro (UNIRIO), atualmente o único curso stricto sensu da área. ${ }^{8}$ Desse modo, a recomendação do grupo que estudou a situação da Arquivologia no Brasil em 1978 ainda é válida quanto à necessidade de projetos que viabilizem a formação de mestres e doutores na área.

Quanto ao controle e à divulgação de acervos arquivísticos, bem como a promoção do acesso à informação e aos documentos públicos, a Lei de Acesso à Informação (LAI) - Lei 12.527, de 18 de novembro de $2011^{9}$ - contempla essas questões, ao demandar, dos arquivos, informações contidas nos documentos por eles custodiadas.

As demais necessidades assinaladas na publicação Avaliação \& Perspectivas de 1982 vêm sendo objeto de pesquisas, no âmbito de cursos de graduação e pós-graduação, conforme temáticas analisadas por Marques e Roncaglio (2012).

\section{Considerações finais}

Desde a sua concepção, os documentos Avaliação \& Perspectivas destacam-se como relevantes instrumentos estratégicos para o desenvolvimento científico e tecnológico do país, funcionando como termômetros científicos das diversas áreas do conhecimento, ao buscar apreender seus problemas, desafios, 
movimentos e avanços, de maneira menos estática que as TACs. Contudo, mesmo com diagnósticos esclarecedores sobre essas áreas, esses documentos parecem ter sido subaproveitados para a tomada de decisões no âmbito da política de C\&T e, infelizmente, após a sua conclusão, não houve iniciativas semelhantes. Como o próprio CNPq reconhece, fica uma "[...] lacuna importante nos processos de avaliação em curso no país." (CONSELHO NACIONAL DE DESENVOLVIMENTO CIENTÍFICO E TECNOLÓGICO, 2002, p. 8).

Verificamos que a publicação Avaliação \& Perspectivas assinala a falsa dicotomia da ausência de práticas na Ciência da Informação, por um lado, e da ausência de teorias na Biblioteconomia e na Arquivologia, por outro lado, ainda que, contraditoriamente, a Ciência da Informação seja apresentada como o campo mais amplo, no qual essas disciplinas aparecem como disciplinas aplicadas. Observamos que a Ciência da Informação parece ter ganhado visibilidade internacional a partir de eventos realizados pela UNESCO e do seu papel na formação de recursos humanos, no desenvolvimento de pesquisas e da sua projeção social. Os documentos criticam, inclusive, a importação acrítica de padrões estrangeiros pelo Brasil.

A Arquivologia e a Biblioteconomia têm suas trajetórias históricas, teóricas e epistemológicas reconhecidas já na primeira versão do documento, publicada em 1978, enquanto a incipiência da Ciência da Informação, no campo científico, aparece na versão de 1982. Todavia, a situação da Arquivologia é resumida no primeiro documento, em dois parágrafos, que apresentam, vagamente, a situação do ensino de graduação e pós-graduação da área; já a Biblioteconomia é sobreposta à Ciência da Informação no segundo documento.

Quanto à Ciência da Informação e à Arquivologia, observamos confusão entre as duas disciplinas, por vezes sobrepostas nas publicações, ainda que descritas separadamente. No caso da Arquivologia, a sua situação é descrita mais superficialmente, se comparada à Ciência da Informação, o que ratifica e intensifica as dificuldades do seu reconhecimento e da sua busca por autonomia, tal como ocorre nas TACs do CNPq.

As questões que subjazem dessas avaliações, como leituras históricas, nos instigam a repensar as perspectivas da Ciência da Informação e da 
Arquivologia, ou seja, os seus rumos teóricos e epistemológicos entre as suas buscas por identidade, reconhecimento e autonomia, associadas às suas alianças, às suas parcerias e a seus diálogos entre si e com outras disciplinas.

Nesse panorama, algumas questões parecem pertinentes, a fim de refletirmos sobre a validade e a proficuidade dessas trilhas para ambas. Afinal, em que medida as interlocuções entre a Ciência da Informação e a Arquivologia respeitam as suas particularidades e as projetam no campo da informação? Essas parcerias também acontecem no cenário internacional ou são específicas do Brasil?

Estas e outras questões ficam como reticências a serem estudadas e analisadas como termômetros dessas disciplinas. Ainda que limitados, os diagnósticos e prognósticos apresentados nos documentos analisados mostramse atuais e importantes, restando-nos, ainda o prognóstico do final dos anos 1970: “[...] a visão que se tem do setor [Ciência da Informação, Biblioteconomia e Arquivologia] é a de um campo ainda por explorar e em que as realizações alcançadas estão muito aquém do que deve ser feito." (CONSELHO NACIONAL DE DESENVOLVIMENTO CIENTÍFICO E TECNOLÓGICO, 1978b, p. 63).

\section{Referências}

ANDRADE, Ana Maria Ribeiro de. História e fonte para a história do CNPq. In: MUSEU DE ASTRONOMIA E ARTES AFINS. Arquivo CNPq (Acervo MAST): inventário sumário. Rio de Janeiro, 1998.

BRASIL. Lei $n^{\circ} 8.159$, de 8 de janeiro de 1991. Dispõe sobre a política nacional de arquivos públicos e privados e dá outras providências. Diário Oficial [da]

República Federativa do Brasil, Brasília, 9 jan. 1991. Retificado no DOU 28 jan. 1991. Disponível em:

$<$ http://www.planalto.gov.br/ccivil 03/leis/L8159.htm>. Acesso em: 13 out. 2016.

BRASIL. Lei $\mathrm{n}^{\circ}$ 12.527, de 18 de novembro de 2011. Regula o acesso a informações previsto no inciso XXXIII do art. 5o, no inciso II do § 3o do art. 37 e no $\S 20$ do art. 216 da Constituição Federal; altera a Lei no 8.112, de 11 de dezembro de 1990; revoga a Lei no 11.111, de 5 de maio de 2005, e dispositivos da Lei no 8.159, de 8 de janeiro de 1991; e dá outras providências. Diário 
Oficial [da] República Federativa do Brasil, Brasília, 18. nov. 2011. Edição extra. Disponível em: < http://www.planalto.gov.br/ccivil 03/ ato20112014/2011/lei/112527.htm>. Acesso em: 13 out. 2016.

COORDENAÇÃO DE APERFEIÇOAMENTO DE PESSOAL DE NÍVEL SUPERIOR. Tabela de Áreas do Conhecimento/Avaliação. Brasília, 2016. Informações disponíveis em: $<$ http://www.capes.gov.br/avaliacao/instrumentosde-apoio/tabela-de-areas-do-conhecimento-avaliacao >. Acesso em: 13 out. 2016.

CONSELHO NACIONAL DE DESENVOLVIMENTO CIENTÍFICO E TECNOLÓGICO. Classificação das áreas do conhecimento. Cadernos de Informação em Ciência e Tecnologia, Brasília, n. 1, jun. 1978a.

CONSELHO NACIONAL DE DESENVOLVIMENTO CIENTÍFICO E TECNOLÓGICO. Avaliação \& Perspectivas. Brasília, 1978 b.

CONSELHO NACIONAL DE DESENVOLVIMENTO CIENTÍFICO E TECNOLÓGICO. Sinopses Avaliação \& Perspectivas. Brasília, 1978c.

CONSELHO NACIONAL DE DESENVOLVIMENTO CIENTÍFICO E TECNOLÓGICO. Avaliação \& Perspectivas. Brasília, 1982a.

CONSELHO NACIONAL DE DESENVOLVIMENTO CIENTÍFICO E TECNOLÓGICO. Avaliação e perspectivas: sinopses. Brasília,1982b.

CONSELHO NACIONAL DE PESQUISA E DESENVOLVIMENTO CIENTÍFICO E TECNOLÓGICO. CNPq: origens e perspectivas. 4. ed. Brasília, 1984.

CONSELHO NACIONAL DE DESENVOLVIMENTO CIENTÍFICO E TECNOLÓGICO. A pesquisa no Brasil: perfil das áreas do conhecimento: humanidades. Brasília, 2002.

DOMINGOS, Manuel. A trajetória do CNPq. Acervo, Rio de Janeiro, v. 17, n. 2, p. 19-40, 2004.

MARQUES, Angelica Alves da Cunha. A Arquivologia brasileira: busca por autonomia no campo da informação e interlocuções internacionais. Rio de Janeiro: AAB, 2013.

MARQUES, Angelica Alves da Cunha; RONCAGLIO, Cynthia. A pesquisa científica em Arquivologia no Brasil. In: MARIZ, Anna Carla de Almeida; JARDIM, José Maria; SILVA, Sérgio Conde de Albite. (Org.). Novas dimensões da pesquisa e do ensino da Arquivologia no Brasil. Rio de Janeiro: Móbile: Associação dos Arquivistas do Estado do Rio de Janeiro, 2012. p. 74-88. 
MOTOYAMA, Shozo. A gênese do CNPq. Revista da Sociedade Brasileira de História da Ciência, São Paulo, n. 2, p. 27-46, jul./dez. 1985.

MOTOYAMA, Shozo; NAGAMINI, Marilda. CNPq e CNRS: duas histórias numa perspectiva comparada (1996). In: HAMBURGER, Amélia Império et al. (Org.). A ciência nas relações Brasil-França (1850-1950). São Paulo: Edusp: FAPESP, 1996. p. 331-359.

OLIVEIRA, Flávia Helena de. A formação em Arquivologia nas universidades brasileiras: objetivos comuns e realidades particulares. 2014. 223 f. Tese (Doutorado em Ciência da Informação) - Universidade de Brasília, Brasília, 2014.

ROMANI, Jacqueline Pitangui. O Conselho Nacional de Pesquisas e Institucionalização da Pesquisa Científica no Brasil. In: SCHWARTZMAN, Simon (Org.). Universidades e instituições científicas no Rio de Janeiro. Brasília: CNPq, 1982. p. 137-167.

SANTOS, Vanderlei Batista dos. Gestão de documentos eletrônicos: uma visão arquivística. 2. ed. rev. e aum. Brasília: ABARQ, 2005.

SOUZA, Kátia Isabelli de B. Melo de. Arquivista, visibilidade profissional: formação, associativismo e mercado de trabalho. Brasília: Starprint, 2011.

SOUZA, Rosali Fernandez de. Áreas do conhecimento. DataGramaZero: Revista de Ciência da Informação, Rio de Janeiro, v. 5, n. 2, abr. 2004.

SOUZA, Rosali Fernandez de. Tabelas de áreas do conhecimento: proposta de metodologia do trabalho de revisão. [S.1.: s.n.], 2005.

SOUZA, Rosali Fernandez de. Organização e representação de áreas do conhecimento em Ciência e Tecnologia: princípios de agregação em grandes áreas segundo diferentes contextos de produção e uso da informação. Encontros Bibli: Revista Eletrônica de Biblioteconomia e Ciência da Informação, Florianópolis, n. esp., p. 27-41, 1. sem. 2006.

SOUZA, Rosali Fernandez de. A Ciência da Informação como área do conhecimento e de fomento no CNPq. In: ENCONTRO NACIONAL DE ENSINO E PESQUISA EM INFORMAÇÃO, 8., 2008, Salvador. Anais... Salvador: [s.n.], 2008.

SOUZA, Rosali Fernandez de; STUMPF, Ida Regina Chitto. Ciência da Informação como área do conhecimento: abordagem no contexto da pesquisa e da Pós-graduação no Brasil. Perspectivas em Ciência da Informação, Belo Horizonte, v. 14, n. esp., p. 41-58, 2009.

UNIVERSIDADE FEDERAL DO ESTADO DO RIO DE JANEIRO. Programa De Pós-Graduação em Gestão de Documentos e Arquivos. Rio de 
Janeiro, RJ, 2016. Disponível em: <http://www.unirio.br/ppgarq >. Acesso em 19 out. 2016.

\title{
Avaliação \& Perspectivas on Information Science and Archival Science in Brazil: reflections in progress
}

\begin{abstract}
This paper aims to comprehend the diagnoses and prognoses of Information Science and Archival Science presented in Avaliação \& Perspectivas. Through bibliographic and documental review in the archive group of the National Council for Scientific and Technological Development $(\mathrm{CNPq})$, it considers the relevance of the publication as a strategic tool for scientific and technological development. It also analyzes the denominations, definitions, relations and recommendations created for these two disciplines in Brazil. More specifically, it retakes the main advances and challenges of Archival Science as a discipline in Brazil. The results indicate denominations sometimes incoherent with the current definitions. The publication points out difficulties of acknowledgement of Information Science and Archival Science in Brazil, although they do not compromise the possibilities of dialogue between them.
\end{abstract}

Keywords: Information Science. Archival Science. Avaliação \& Perspectivas. CNPq. Scientific development.

Recebido: $27 / 07 / 2016$

Aceito: 05/09/2016

${ }^{1}$ Este artigo resulta das atividades de estágio pós-doutoral financiado pela Coordenação de Aperfeiçoamento de Pessoal de Nível Superior (Bolsista da CAPES - Proc. n BEX 2347/156). Compõe, também, as atividades do grupo de pesquisa Fundamentos Históricos, Epistemológicos e Teóricos da Arquivologia (FHETA) e do grupo Informação, Estado e Sociedade (EIS) da Universidade de Brasília (UnB).

2 A trajetória histórica do CNPq é detalhadamente apresentada por Motoyama (1985) e Motoyama e Nagamini (1996). Andrade (1998) e Domingos (2004) também a apresentam criticamente.

3 Informações sobre a TAC disponíveis na página "Tabela de Áreas do Conhecimento/Avaliação" da Capes (COORDENAÇÃO DE APERFEIÇOAMENTO DE PESSOAL DE NÍVEL SUPERIOR, 2016).

4 A professora Suzana Mueller dedica-se à redação da parte do texto relativa à Ciência da Informação e da Biblioteconomia, enquanto Nilza Teixeira Soares, então da Coordenação de Arquivo da Câmara dos Deputados, redige a parte da Arquivologia.

${ }^{5}$ Informações disponíveis em: <http://www.planalto.gov.br/ccivil_03/leis/L8159.htm>. Acesso em: 13 out. 2016. 
${ }^{6}$ Associação Brasiliense de Arquivologia (ABARQ), Associação de Arquivistas de São Paulo (ARQ-SP), Associação dos Arquivistas do Estado do Rio Grande do Sul (AARS), Associação dos Arquivistas da Bahia (AABA), Associação dos Arquivistas do Estado do Rio de Janeiro (AAERJ), Associação dos Arquivistas do Estado do Espírito Santo (AARQES), Associação dos Arquivistas do Estado do Paraná (AAPR), Associação de Arquivologia do Estado de Goiás (AAG), Associação dos Arquivistas do Estado do Ceará (ARQUIVE-CE), Associação dos Arquivistas do Estado de Santa Catarina (AAESC), Associação dos Arquivistas da Paraíba (AAPB) e Associação Mineira de Arquivistas (AMARQ).

${ }^{7}$ Dezesseis cursos de graduação em Arquivologia estão distribuídos em universidades públicas: Universidade Federal do Estado do Rio de Janeiro (UNIRIO), Universidade Federal de Santa Maria (UFSM), Universidade Federal Fluminense (UFF), Universidade de Brasília (UnB), Universidade Estadual de Londrina (UEL), Universidade Federal da Bahia (UFBA), Universidade Federal do Rio Grande do Sul (UFRGS), Universidade Federal do Espírito Santo (UFES), Universidade Estadual Paulista Júlio de Mesquita Filho (UNESP/Marília), Universidade Estadual da Paraíba (UEPB), Universidade Federal da Paraíba (UFPB), Fundação Universidade do Rio Grande do Sul (FURG), Universidade Federal de Minas Gerais (UFMG), Universidade Federal do Amazonas (UFAM), Universidade Federal de Santa Catarina (UFSC) e Universidade Federal do Pará (UFPA). Somente um curso funciona, atualmente, em faculdade particular, o do Centro Universitário Assunção (UNIFAI).

${ }^{8}$ Informações sobre o PPGARQ disponíveis em: <http://www2.unirio.br/unirio/cchs/ppggda>. Acesso em: 21 jul. 2016.

${ }^{9}$ Informações sobre a LAI disponíveis na página da Presidência da República (BRASIL, 2011). 